\title{
Macroangiopathy and Associated Factors in Outpatients with Type 2 Diabetes Attending the Antidiabetic Center of Abidjan in Ivory Coast
}

\author{
Aké-Tano Sassor Odile Purifine $e^{1,2, *}$, Ekou Franck Kokora ${ }^{1,2}, K_{\text {Kpebo Djoukou Olga Denise }}^{1,2}$, \\ Aka Felix ${ }^{1}$, Konan Yao Eugène ${ }^{1,2}$, Tetchi Ekissi Orsot ${ }^{1,2}$, Sablé Parfait Sable ${ }^{1,2}$, Malan Léa ${ }^{1}$, \\ Kouassi Dinard ${ }^{1}$ \\ ${ }^{1}$ National Institute of Public Health, Abidjan, Ivory Coast \\ ${ }^{2}$ Public Health and Biostatistics Department, Training and Research Unit of Medical School, University Félix Houphouet Boigny, Abidjan, \\ Ivory Coast
}

\section{Email address:}

odileake@yahoo.fr (Aké-Tano S. O. P.)

${ }^{*}$ Corresponding author

\section{To cite this article:}

Aké-Tano Sassor Odile Purifine, Ekou Franck Kokora, Kpebo Djoukou Olga Denise, Aka Felix, Konan Yao Eugène, Tetchi Ekissi Orsot, Sablé Parfait Sable, Malan Léa, Kouassi Dinard. Macroangiopathy and Associated Factors in Outpatients with Type 2 Diabetes Attending the Antidiabetic Center of Abidjan in Ivory Coast. Science Journal of Public Health. Vol. 5, No. 4, 2017, pp. 347-352. doi: $10.11648 /$ j.sjph.20170504.21

Received: May 16, 2017; Accepted: June 1, 2017; Published: July 21, 2017

\begin{abstract}
Diabetes constitutes a major public health concern, especially in developing countries, due to its frequency and severity related to the macroangiopathy complications. This study aimed at estimating the prevalence of macroangiopathy in type 2 diabetic outpatients attending the Antidiabetic Center of Abidjan (ADCA) and identifying the associated factors. It was a retrospective and analytic study that was conducted in 2014 at the ADCA. In total, 377 diabetic outpatients were included in the study. Patients had a mean age of 61.3 (SD: 8.9) years and were suffering diabetes for a mean duration of 11.8 years (SD: 5.6). In $95.5 \%$ of the cases, at least one cardiovascular disease risk factor was associated to diabetes. It was high level of cholesterol (37.1\%), high level of Low Density Lipoprotein (LDL) cholesterol (72.4\%), low level of High Density Lipoprotein (HDL) cholesterol (20.9\%), high level of triglycerides (10.3\%), hypertension (67.4\%), and obesity (18.8\%). Macroangiopathy was diagnosed in 62 out of 377 patients, meaning $16.4 \%$. It was a coronary disease (44/377 meaning 11.7\%), vascular cerebral accident (11/377 meaning 2.9\%) and peripheral arterial disease of the lower limbs (10/377 meaning 2.7\%). Diabetic patients with hypertension were more likely to have a macroangiopathy as compared to those without hypertension $(\mathrm{p}=0.024$; OR2.57, $\mathrm{IC}=[1.13-5.85])$. In addition, patients presenting a low level of HDL cholesterol were likely to have a coronary heart disease as compared to those with a normal level of HDL cholesterol $(p=0.008)$; OR $=2.72$, IC [1.28-5.76]. With regard to the severity of macroangiopathy complications, it is tremendous to reinforce the medical management of cardiovascular disease risk factors in type 2 diabetes patients in Ivory Coast.
\end{abstract}

Keywords: Type 2 Diabetes, Macroangiopathy, Associated Factors, Ivory Coast

\section{Introduction}

In contrast to a former opinion that was considering diabetes mellitus as a disease of developed countries, it has more and more become a major health concern in developing countries. In fact, the recent global estimates of the International Federation of Diabetes (IFD) reveal that $8.3 \%$ of adults, meaning 382 million people are affected with diabetes worldwide, type 2 diabetes being the leading condition [1]. These figures are expected to increase beyond 592 million in less than 25 years. Moreover, $80 \%$ of the total number of people affected with this disease live in poor and middle income countries such as Cote d'Ivoire where the epidemic is growing at an alarming pace, along with its related complications, representing a heavy social and 
economic burden [1].

Among the complications, macroangiopathy with regards to its frequency and severity, represents a major concern. According to several epidemiologic studies, macroangipathy accounts for more than half the deaths observed in the diabetic population [2]. In the United States of America (USA), this coronary heart disease brings about $70 \%$ of deaths in type 2 diabetes patients while it is only responsible of one-third of deaths in non-diabetic patients [2]. In France, it is usually estimated that $20-30 \%$ of type 2 diabetes patients are affected with an ischemic coronary heart disease. In addition, diabetic patients are 4 to 6 times likely to suffer a peripheral arterial disease (PAD) of the lower limbs as compared to non-diabetic patients [1]. This frequency of macroangiopathy is explained by the steady presence of cardiovascular disease risk factors among type 2 diabetic patients, hypertension being the leading risk factor with $60 \%$ to $70 \%$ of patients concerned [3]. Hence, a noticeable number of deaths could be avoided in the diabetic population by decreasing their risk level of cardiovascular disease.

In Ivory Coast, the estimate prevalence of macroangiopathy in 2002 was $23.15 \%$ [4]. Except this study, there is a scarcity of recent data on the prevalence of macroangiopathy in diabetic patients, and above all, little is known on the associated risk factors. This study has been conducted with the aim of filling such a gap. The objectives were to estimate the prevalence of macroangiopathy in type 2 diabetic patients followed in the Antidiabetic Center of Abidjan (ADCA) and to identify its related risk factors.

\section{Methodology}

\subsection{Study Site}

The study site was the Antidiabetic Center of Abidjan (ADCA) located at the National Institute of Public Health (NIPH) is the national reference center specialized in the management of diabetic outpatients (both type 1 and type 2). Each year, this center receives about 1500 new cases and follows up the management of 10.000 consulting of diabetes. The majority of patients, meaning $93.4 \%$ are type 2 diabetes patients.

The ADCA offers a comprehensive medical management of the diabetic population. It is organized so as to offer in the same venue, a minimum annual package of care including medical and nutritional care as well as exams related to the follow up and checkup (biology, ECG) for 55000 FCFA, meaning about 90 USD considering the current cost of 1 $\mathrm{USD}=607$ FCFA). The medical care are provided by a team made of 8 doctors, 3 nurses, and one social worker.

\subsection{Type of Study}

It was a retrospective descriptive and analytic study. The study was conducted during the month of November 2014.

\subsection{Study Population and Sampling Strategy}

The study population was made of type 2 diabetes patients attending the ADCA. Any patient respecting the following criteria was included:

(a) attended the ADCA in 2014;

(b) with a diabetes duration of 5 years and more;

(c) benefited a screening for macroangiopathy related complications.

The sample size was calculated based on the formula below:

$$
n=\frac{\varepsilon^{2} p q}{i^{2}}=377
$$

$\mathrm{p}$ is the expected proportion of macroangiopathy $56.86 \%$ [5]

$\mathrm{q}=1-\mathrm{p}$

$\mathcal{E}$ is the standard normal variate at the risk $\alpha$ (type 1 error) of $5 \%=1.96$

$\mathrm{i}$ is the precision used to estimate the frequency of macroangiopathy $=5 \%$.

The minimum number of subjects to include in the study was 377. Patients were retrospectively included, going from the beginning date of the survey, until the desired sample size was reached. Thus, they were retrospectively included based on their order in the registration files.

\subsection{Data Collected}

Sources of data were the medical records of the patients. Data were collected through a questionnaire and were related to sociodemographic characteristics (age, sex, profession, nationality, ethnicity, marital status, place of residency), diabetes history (diagnosis circumstances, family history of diabetes, diabetes duration, duration of ADCA attendance, current treatment, the most recent blood sugar measure, HBA1c), associated cardiovascular disease risk factors (hypertension, dyslipidemia, obesity, overweight, smoking, micro or macro albumineria), macroangiopathy related complications (coronary heart disease, cerebral vascular disease, peripheral arterial disease of the lower limbs) and other complications (microangiopathy, metabolic and infectious complications).

\subsection{Definition of Mains Variables}

Coronary heart disease: Coronary heart disease diagnosis was made in front of electrocardiogram abnormalities revealing an ischemia, a lesion or a necrosis.

Cerebral Vascular Disease (CVD): CVD diagnosis was made when intracranial computed tomography scans were showing typical images of stroke or in front of sequelae of stroke such as motor deficiency (hemiparesis and hemiplegia).

Peripheral Arterial Disease of the lower limbs (PAD of the lower limbs): Diagnosis of PAD of the lower limbs was made in front of typical clinical symptoms (absence of one or several pulses at the palpation of lower limbs arteries, intermittent claudication, rest pain, skin discoloration / gangrene) and/or typical results of the duplex Doppler of the lower limbs.

Hypertension: Hypertension was defined as systolic blood 
pressure superior or equal to $140 \mathrm{mmHg}$ and/or diastolic blood pressure less or equal to $90 \mathrm{mmHg}$.

Dyslipidemia: Dyslipidemia was diagnosed in presence of at least one of the following abnormality, total cholesterol superior or equal to $2.0 \mathrm{~g} / 1$ or Low Density Lipoprotein (LDL) cholesterol superior to $1.0 \mathrm{~g} / \mathrm{l}$; High Density Lipoprotein (HDL) cholesterol $<0.4 \mathrm{~g} / 1$ for men and $0.5 \mathrm{~g} / 1$ for women; Triglycerides superior to $1.5 \mathrm{~g} / \mathrm{l}$.

Glycemic balance: Glycemic balance was defined by a level of HbA1c less than or equal to $7 \%$.

Obesity: the patient was considered obese when his Body Mass Index (BMI) was superior or equal to $30 \mathrm{~kg} / \mathrm{m}^{2}$.

\subsection{Data Management}

Data were entered and analyzed using Epidata 3.1, SPSS 18.0 and Excel 2007. Quantitative variables were described by the mean, the standard deviation and the extremes. Qualitative variables were described by the proportions. In order to identify the correlates factors of macroangiopathy, we've first conducted a bivariate analysis with the test of chi 2 . Then, variables showing a significant association with the dependent variable as well as those described in the literature as potential predictors of macroangiopathy related complications were included in the model for the multivariate logistic regression.

In the final model, adjusted Odds Ratio (OR) and their Confidence Interval (CI) at $95 \%$ were computed. The statistics tests were realized at the significant statistic level of $5 \%$.

\subsection{Ethical Considerations}

We have obtained an authorization of the direction of NIPH that has allowed us to conduct this survey in the ADCA. We have respected the anonymity of the questionnaires and confidentiality during data collection.

\section{Results}

\subsection{General Characteristics of the Study Population}

General characteristics of the study population are described in table 1 . The majority of patients were female $(62.1 \%)$ with a sex ratio of 0.61 . The mean age was 61.27 [ \pm $8.9]$ years and the majority was Ivorian $(91.8 \%)$. About one quarter $(24.1 \%)$ of the study population were either retired or unemployed and more than 2-third were married (71.9\%) and were living in Abidjan (70.9\%). Diabetes was discovered in a context of cardinal symptoms $(78.8 \%)$, with a mean duration of $11.78[ \pm 5.6]$ years. Family history of diabetes was found in $35.8 \%$ of cases and was mainly concerned with ascendants (52.3\%) and siblings (45.7\%).

The mean duration of attendance to the ADCA was 10.01 [ \pm 6.2] years. Patients' treatment was mainly based on Oral Anti-diabetic (50.9\%) and insulin only $(34.2 \%)$. The last 3 months' glycemic balance (HbA1c $\leq 7 \%$ ) was satisfying in $56.8 \%$ of patients.

In $95.5 \%$ of the cases, at least one cardiovascular disease risk factor was associated to diabetes. It was high level of cholesterol (37.1\%), high level of LDL cholesterol (72.4\%), low level of HDL cholesterol (20.9\%), high level of triglycerides $(10.3 \%)$, hypertension $(67.4 \%)$, and obesity (18.8\%). More than 2-thirds of patients were presenting a dyslipidemia $(70.5 \%)$

Table 1. General Description of diabetic patients, ADCA, 2014.

\begin{tabular}{|c|c|c|}
\hline Variables & Frequency & $\%$ \\
\hline \multicolumn{3}{|l|}{ Sex } \\
\hline Male & 143 & 37.9 \\
\hline Female & 234 & 62.1 \\
\hline \multicolumn{3}{|l|}{ Age (years) } \\
\hline $40-49$ & 32 & 8.5 \\
\hline $50-59$ & 136 & 36.1 \\
\hline $60-69$ & 149 & 39.5 \\
\hline$\geq 70$ & 60 & 15.9 \\
\hline \multicolumn{3}{|l|}{ Place of residency } \\
\hline Abidjan & 267 & 70.9 \\
\hline Out of Abidjan & 110 & 29.1 \\
\hline \multicolumn{3}{|l|}{ Circonstances of diagnosis } \\
\hline Cardinal symptoms & 297 & 78.8 \\
\hline Fortuitous discovery & 71 & 18.8 \\
\hline Complications & 9 & 2.4 \\
\hline \multicolumn{3}{|l|}{ Diabetes duration (years) } \\
\hline$<10$ & 158 & 41.9 \\
\hline$\geq 10$ & 219 & 58.1 \\
\hline \multicolumn{3}{|l|}{ Current anti-diabetic treatment } \\
\hline Oral Anti Diabetic drugs (OAD) & 192 & 50.9 \\
\hline Insuline & 129 & 34.2 \\
\hline $\mathrm{OAD}+$ insuline & 37 & 9.8 \\
\hline Nutritional Education Measures & 19 & 5.1 \\
\hline \multicolumn{3}{|l|}{ Obesity $^{1}$} \\
\hline Absent & 294 & 81.2 \\
\hline Present & 68 & 18.8 \\
\hline \multicolumn{3}{|l|}{ Hypertension } \\
\hline Absent & 123 & 32.6 \\
\hline Present & 254 & 67.4 \\
\hline \multicolumn{3}{|l|}{$\mathrm{HbAl} \mathrm{c}^{2}$} \\
\hline$<7 \%$ & 197 & 54.6 \\
\hline$\geq 7 \%$ & 164 & 45.4 \\
\hline \multicolumn{3}{|l|}{ Total Cholesterol $^{3}$} \\
\hline$<2.0 \mathrm{~g} / 1$ & 215 & 62.9 \\
\hline$\geq 2.0 \mathrm{~g} / 1$ & 127 & 37.1 \\
\hline \multicolumn{3}{|l|}{ LDL Cholesterol $^{4}$} \\
\hline$<1.0 \mathrm{~g} / 1$ & 94 & 27.6 \\
\hline$\geq 1.0 \mathrm{~g} / 1$ & 246 & 72.4 \\
\hline \multicolumn{3}{|l|}{ HDL Cholesterol $^{4}$} \\
\hline$<0.40 \mathrm{~g} / 1$ & 71 & 20.9 \\
\hline$\geq 0.40 \mathrm{~g} / 1$ & 269 & 79.1 \\
\hline \multicolumn{3}{|l|}{ Triglycerides ${ }^{5}$} \\
\hline$<1.50 \mathrm{~g} / 1$ & 306 & 89.7 \\
\hline$\geq 1.50 \mathrm{~g} / 1$ & 35 & 10.3 \\
\hline
\end{tabular}

${ }^{1} \mathrm{n}=362{ }^{2} \mathrm{n}=361{ }^{3} \mathrm{n}=342{ }^{4} \mathrm{n}=340{ }^{5} \mathrm{n}=341$

\subsection{Macroangiopathy and Associated Risk Factors}

Macroangiopathy was diagnosed in 62 out of 377 patients, meaning $16.4 \%$. It was, in a ranking order, coronary heart disease (44 meaning 11.7\%), cerebral vascular disease (11 meaning $2.9 \%$ ), and peripheral arterial disease of the lower limbs (10 meaning 2.7\%). Most of the macroangiopathy related complications (75.8\%) occurred after 5 years of diabetes duration. Macroangiopathy was more frequent in patients aged 65 years and more $(p=0.003)$, those with more than 10 years of diabetes duration $(p=0.025)$, and those with 
an associated hypertension (0.006) (Table 2).

Table 2. Macroangiopathy according to diabetic patients' characteristics, $A D C A, 2014$

\begin{tabular}{llll}
\hline Variables & Frequency & $\mathbf{\%}$ & $\mathbf{p}$ \\
\hline Sex & & & \\
Male & 24 & $16.8 \%$ & 0.89 \\
Female & 38 & $16.2 \%$ & \\
Age & & & \\
$<65$ & 30 & $12.3 \%$ & 0.003 \\
$\geq 65$ & 32 & $24.1 \%$ & \\
Diabetes duration (years) & & & \\
$<10$ & 18 & $11.4 \%$ & 0.025 \\
$\geq 10$ & 44 & $20.1 \%$ & \\
HbA1c & & & \\
$<7 \%$ & 35 & $17.8 \%$ & 0.744 \\
$\geq 7 \%$ & 27 & $16.5 \%$ & \\
Hypertension & & & \\
Yes & 51 & $20.1 \%$ & 0.006 \\
No & 11 & $8.9 \%$ & \\
LDL Cholesterol & & & \\
$<1.0 \mathrm{~g} / 1$ & 17 & $18.1 \%$ & 0.433 \\
$\geq 1.0 \mathrm{~g} / 1$ & 36 & $14.6 \%$ & \\
HDL Cholesterol & & & \\
$<0.40 \mathrm{~g} / 1$ & 16 & $22.5 \%$ & 0.070 \\
$\geq 0.40 \mathrm{~g} / 1$ & 37 & $13.8 \%$ & \\
Triglycerides & & & \\
$<1.50 \mathrm{~g} / 1$ & 45 & $14.7 \%$ & 0.207 \\
$\geq 1.50 \mathrm{~g} / 1$ & 8 & $22.9 \%$ & \\
Obesity & & & \\
Yes & 14 & $20.6 \%$ & 0.32 \\
No & 46 & $15.7 \%$ & \\
\hline
\end{tabular}

After adjusting for age, diabetes duration and the levels of LDL cholesterol, HDL cholesterol and triglycerides, there was a significant association between macroangiopathy and hypertension ( $\mathrm{p}=0.024$; OR2.573, IC $=[1.132-5.846])$. Diabetic patients with hypertension were 2 times more likely to suffer from macroangiopathy as compared to those without hypertension (Table 3).

Table 3. Factors associated with macroangiopathy ( $n=377$; number of cases macroangiopathy $=62$ )

\begin{tabular}{|c|c|c|c|}
\hline Variables & OR & IC $95 \%$ & p value \\
\hline \multicolumn{4}{|l|}{ Age (years) } \\
\hline$<65$ & 1 & --- & \\
\hline$\geq 65$ & 0.605 & {$[0.322-1.136]$} & 0.118 \\
\hline \multicolumn{4}{|c|}{ Hypertension } \\
\hline Absent & 1 & --- & \\
\hline Present & 2.421 & {$[1.071-5.473]$} & 0.034 \\
\hline \multicolumn{4}{|c|}{ Diabetes duration (years) } \\
\hline$<10$ & 1 & --- & \\
\hline$\geq 10$ & 0.601 & {$[0.306-1.181]$} & 0.140 \\
\hline \multicolumn{4}{|l|}{ HbAlc } \\
\hline$<7 \%$ & 1 & --- & \multirow{2}{*}{0.822} \\
\hline$\geq 7 \%$ & 0.932 & {$[0.503-1.725]$} & \\
\hline \multicolumn{4}{|c|}{ LDL Cholesterol } \\
\hline$<1.0 \mathrm{~g} / 1$ & 1 & --- & \\
\hline$\geq 1.0 \mathrm{~g} / 1$ & 1.231 & {$[0.631-2.401]$} & 0.542 \\
\hline \multicolumn{4}{|c|}{ HDL Cholesterol } \\
\hline$<0.40 \mathrm{~g} / 1$ & 0.518 & {$[0.262-1.024]$} & \\
\hline$\geq 0.40 \mathrm{~g} / 1$ & 1 & --- & 0.058 \\
\hline \multicolumn{4}{|c|}{ Triglycerides } \\
\hline$<1.49 \mathrm{~g} / 1$ & 1 & --- & \\
\hline$\geq 1.50 \mathrm{~g} / 1$ & 0.701 & {$[0.277-1.777]$} & 0.455 \\
\hline
\end{tabular}

Table 4. Coronary heart disease according to diabetic patients characteristic, ADCA, 2014

\begin{tabular}{|c|c|c|c|}
\hline Variables & Effectif & $\%$ & $\mathbf{p}$ \\
\hline \multicolumn{4}{|l|}{ Sex } \\
\hline Male & 18 & $12.6 \%$ & \multirow{2}{*}{0.66} \\
\hline Female & 26 & $11.1 \%$ & \\
\hline \multicolumn{4}{|l|}{ Age (years) } \\
\hline$<65$ & 21 & $8.6 \%$ & \multirow{2}{*}{0.012} \\
\hline$\geq 65$ & 23 & $17.3 \%$ & \\
\hline \multicolumn{4}{|c|}{ Diabetes duration (years) } \\
\hline$<10$ & 13 & $8.2 \%$ & \multirow{2}{*}{0.077} \\
\hline$\geq 10$ & 31 & $14.2 \%$ & \\
\hline \multicolumn{4}{|l|}{$\mathrm{HbA1c}$} \\
\hline$<7 \%$ & 24 & $11.8 \%$ & \multirow{2}{*}{0.779} \\
\hline$\geq 7 \%$ & 20 & $12.7 \%$ & \\
\hline \multicolumn{4}{|c|}{ Hypertension } \\
\hline Absent & 9 & $7.3 \%$ & \multirow{2}{*}{0.067} \\
\hline Present & 35 & $13.8 \%$ & \\
\hline \multicolumn{4}{|c|}{ LDL Cholesterol } \\
\hline$<1.0 \mathrm{~g} /$ & 11 & $11.7 \%$ & \multirow{2}{*}{0.764} \\
\hline$\geq 1.0 \mathrm{~g} / 1$ & 26 & $10.6 \%$ & \\
\hline \multicolumn{4}{|c|}{ HDL Cholesterol } \\
\hline$<0.40 \mathrm{~g} / 1$ & 14 & $19.7 \%$ & \multirow{2}{*}{0.007} \\
\hline$\geq 0.40 \mathrm{~g} / 1$ & 23 & $8.6 \%$ & \\
\hline \multicolumn{4}{|c|}{ Triglycerides } \\
\hline$<1.49 \mathrm{~g} / 1$ & 30 & $9.8 \%$ & \multirow{2}{*}{0.066} \\
\hline$\geq 1.50 \mathrm{~g} / 1$ & 7 & $20.0 \%$ & \\
\hline \multicolumn{4}{|l|}{ Obesity } \\
\hline Yes & 12 & $17.6 \%$ & \multirow{2}{*}{0.084} \\
\hline No & 30 & $10.2 \%$ & \\
\hline
\end{tabular}

Coronary heart disease was associated with age $(\mathrm{p}=0.012)$ and level of HDL cholesterol $(\mathrm{p}=0.007)$ in the bivariate analysis (Table 4). After adjusting for age, diabetes duration, hypertension, level of LDL cholesterol, and level of triglycerides, we found that level of HDL cholesterol was significantly associated with coronary heart disease ( $\mathrm{p}=$ 0.008); OR = 2.720, IC [1.284-5.762] (Table 5). Patients with low level of HDL cholesterol $(<0.40 \mathrm{~g} / \mathrm{l})$ were about 3 times more likely to suffer from coronary heart disease.

Table 5. Factors associated to coronary heart disease ( $n=377$; cases of coronary heart disease $=44$ ).

\begin{tabular}{llll}
\hline Variables & OR & IC & p value \\
\hline $\begin{array}{l}\text { Age (years) } \\
<65\end{array}$ & 1 & --- & \\
$\geq 65$ & 1.640 & {$[0.784-3.433]$} & 0.189 \\
$\begin{array}{l}\text { Diabetes duration (years) } \\
<10\end{array}$ & 1 & -- & \\
$\geq 10$ & 1.448 & {$[0.664-3.154]$} & 0.352 \\
Hypertension & & & \\
Absent & 1 & --- & \\
Present & 0.587 & {$[0.240-1.436]$} & 0.243 \\
HbA1c & & & \\
$<7 \%$ & 1 & --- & 0.301 \\
$\geq 7 \%$ & 1.460 & {$[0.713-2.989]$} & \\
LDL Cholesterol & & & \\
$<1.0 \mathrm{~g} / 1$ & 1 & --- & 0.997 \\
$\geq 1.0 \mathrm{~g} / 1$ & 0.992 & {$[0.449-2.211]$} & \\
HDL Cholesterol (n=340) & & & 0.006 \\
$<0.40 \mathrm{~g} / 1$ & 2.879 & {$[1.362-6.089]$} & \\
$\geq 0.40 \mathrm{~g} / 1$ & 1 & --- & 0.188 \\
\hline $\begin{array}{l}\text { Triglycerides }(\mathrm{n}=341) \\
<1.49 \mathrm{~g} / 1\end{array}$ & 1 & --- & \\
$\geq 1.50 \mathrm{~g} / 1$ & 1.965 & {$[0.720-5.364]$} & \\
\hline
\end{tabular}




\section{Discussion}

This study realized in ADCA, the national reference center for management of diabetes outpatients, aimed at estimating the prevalence of macroangiopathy in type 2 diabetes patients, as well as identifying the associated risk factors of macroangiopathy in type 2 diabetes patients.

This study showed some limitations. Some paraclinical exams that could help in exploring and confirming some complications were not systematically prescribed to or realized by patients.

In addition, some information related to macroangiopathy and its risk factors were lacking in some medical records. This may have influenced the prevalence of some macroangiopathy related complications and may have limited data analysis. In spite of these limitations, the study has revealed some sound results that can help in decision making at the local level.

In the study, patients presented at least one associated Cardiovascular Disease Risk Factor (CVDRF) such as hypertension $(67.4 \%)$, dyslipidemia $(70.5 \%)$ and obesity $(18.8 \%)$.

These results are similar to those found in the literature, revealing that hypertension is present in $20 \%$ to $80 \%$ of diabetic patients [2] and dyslipidemia in 54\% [2,6]. The frequency of CVDRF in diabetic patients can be explained by the fact that type 2 diabetes generally occurs in a context of several metabolic abnormalities or metabolic syndrome due to insulin resistance.

These cardiovascular risk factors expose diabetic patients to the occurrence of macroangiopathy related complications, explaining all the severity of this condition. In the study, $16.4 \%$ of patients presented macroangiopathy related complications. The results are different from those of past studies realized in type 2 diabetes patients in Ivory Coast.

Studies realized at the teaching Hospital of Treichville in 1993, 1999 and 2002 respectively found prevalence of macroangiopathy of $56.86 \%$ [5], 34.33\% [7], et $23.15 \%$ [4].

These results show a reduction in the prevalence of macroangiopathy throughout the years. In contrast, ABODO, in a study conducted in a peripheral hospital of Abidjan, found a prevalence of $5.1 \%$ [8]. This low prevalence may be explained by the fact that this facility did not have a specialized technical plateau, and was therefore referring patient to more specialized structures such as ADCA and the unit of diabetology of the teaching hospital. The current study showed that coronary heart disease $(11.7 \%)$ was the most frequent complication. These findings are similar to those of study conducted by Allechi in Ivory Coast and Ouedraogo in Burkina Faso with respective prevalence of $20.78 \%$ and $32.2 \%[5,9,10]$.

In Morocco, FILALI in 2009, in a study on type 2 diabetes patients at the teaching Hospital of Marrakech, showed a proportion of «coronary» complications of $24.5 \%$ [11]. In France, the ENTRED study in 2007 showed a prevalence of coronary heart disease of $15.5 \%$ in the general population [12].
The prevalence of coronary heart disease in diabetic patient is as higher as other CVDRF are present and it is higher than $50 \%$ when two other risk factors are associated to diabetes $[13,14]$. Vascular cerebral disease and PAD of the lower limbs were present in the study population at some relatively low prevalence, respectively of $2.9 \%$ and $2.7 \%$.

KONIN, in a prospective study conducted in 2012 in diabetic patients coming from 3 diabetes management centers in Abidjan, found a prevalence of PAD of the lower limbs higher than ours (22.07\%) [15].

In Morocco, FILALI in his study revealed some proportions of vascular cerebral disease and PAD of the lower limbs at $22.1 \%$ and $13.9 \%$ respectively [11]. In this study, the diagnosis of PAD of the lower limbs was essentially clinically made. Paraclinical exams such as Duplex Doppler of the lower limbs were barely prescribed or realized, explaining this low proportion. According to the results, hypertension was significantly associated with macroangiopathy related complications. Henceforth, diabetic patients with hypertension were 2.4 more likely to suffer some macroangiopathy related complication as compared to diabetic patients without hypertension.

According to the literature, hypertension is a major risk factor of coronary heart disease in diabetic patients: an increase in systolic blood pressure of $10 \mathrm{mmHg}$ is associated to a $15 \%$ increase in risk of coronary heart disease [16]. Hypertension is responsible of $49 \%$ of cardiovascular ischemic disease and $62 \%$ of vascular cerebral disease [17].

With regards to coronary heart disease, there is a significant association with the risk factor HDL Cholesterol. Low level of HDL cholesterol in a diabetic patient increases 2.8 times the risk of suffering a coronary heart disease. In 1993, the National Cholesterol Education Program (NCEP) Adult Treatment Panel II (ATP II) recognized HDL cholesterol as a risk factor of independent ischemic cardiovascular disease and recommended its dosage along with that of total cholesterol during the initial screening [18]. High level of cholesterol is responsible of $18 \%$ of vascular cerebral diseases and $56 \%$ of ischemic cardiovascular diseases [16].

\section{Conclusion}

Hypertension and low level of HDL cholesterol were identified as predictors of macroangiopathy in diabetic patients attending the ADCA. More than 2 thirds were suffering from hypertension and had low level of HDL cholesterol. With regards to the severity of macroangiopathy complications, it appears tremendous to reinforce the medical management of diabetic patients. This will require to prevent the onset of cardiovascular disease risk factors by the educational and hygienic strategies or to radically treat them once they are already set. In addition, all cardiovascular complications should be systematically and efficiently looked after in diabetic patients so as to ensure an early management. 


\section{References}

[1] Fédération Internationale du Diabète. Atlas du diabète de la FID. 6è éd; 2013. Available on: http://www.idf.org/diabetesatlas

[2] Grimaldi A. Traité de diabétologie. 2è Ed. Paris: MédecineSciences Flammarion, 2009: 1044p.

[3] Sowers JR, Epstein M, Frohlich ED. Diabetes, hypertension, and cardiovascular disease: an update. Hypertension. 2001; 37 (4): 1053-9.

[4] Legret D. Le diabète du sujet âgé en Côte d'Ivoire [thèse Med]. Abidjan: U. F. R des Sciences Médicales; 2002, $\mathrm{n}^{\circ} 3105.209 \mathrm{p}$.

[5] Allechi C. Formes clinques du diabète sucré à Abidjan: Etude typologique de 1000 cas [thèse Med]. Abidjan, 1993, n ${ }^{\circ} 1484$. 256 .

[6] Deconinck B, Mathieu C, Benhalima K. Characteristics and cardiovascular complications of a large cohort of adults diagnosed with type 2 diabetes $<45$ years. Diabetol Metab Syndr 2017; 9: 28. doi 10.1186/s13098-017-0227-z.

[7] Sibailly P. Contribution à l'étude des complications du diabète sucré en Côte d'Ivoire. Etude transversale chez 300 patients [thèse Med]. Abidjan, 1998, n²172.350 p.

[8] Abodo J. Aspects du diabète sucré chez le noir africain à l'Hôpital Militaire d'Abidjan à propos de 473 cas colligés du $1^{\mathrm{er}}$ janvier 1995 au 31 décembre 1999 [thèse Med]. Abidjan, $2000, \mathrm{n}^{\circ} 2635.212 \mathrm{p}$.

[9] Aphala O. Bilan de 40 années d'activités de prise en charge du diabète en Côte d'Ivoire: caractéristiques épidémiologiques et cliniques des patients suivis au Centre Antidiabétique d'Abidjan (CADA). Diabetes \& Metabolism 2016; 42 , Supplement 1: A24-A25.
[10] Ouédraogo S. Etude des atteintes cardio-vasculaires au cours du diabète de sucré au Centre Hospitalier National Sanon Souro de Bobo-Dioulasso [thèse Med]. Ouagadougou, 1997, $\mathrm{n}^{\circ} 15.229 \mathrm{p}$.

[11] Filali BK, Ouhadouche F, Diouri A. La macro-angiopathie chez le diabétique: Profil clinique et épidémiologique. À propos de 122 cas. Diabetes \& Metabolism 2009; 35, Supplement 1: A78.

[12] Druet C. Echantillon national témoin représentatif des personnes diabétiques. Entred 2007-2010. Saint-Maurice: Institut de veille sanitaire; $2012.8 \mathrm{p}$.

[13] Stamler J, Vaccaro O, Neaton J, Wentworth D. Diabetes, other risk factors and 12 years cardiovascular mortality for men screened in the Multiple Risk Factor Intervention Trial. Diabetes Cares 1993; 16: 434-44.

[14] Bertoluci CM, Rocha ZV. Cardiovascular risk assessment in patients with diabetes. Diabetol Metab Syndr 2017; 9: 25. doi 10.1186/s13098-017-0225-1.

[15] Konin C, N'Loo EAS, Adoubi A, Coulibaly I, N'Guetta R, Boka B et all. Artériopathie des Membres Inférieurs du diabétique noir africain: aspects ultrasoniques et facteurs déterminants. Journal des Maladies Vasculaires 2014; 39: 37381 .

[16] Turner RC, Millins H, Stratton IM et al. Risk factors for coronary artery disease in non-insulin dependent diabetes mellitus: UKPDS 23. BMJ 1998; 316: 823-82.

[17] Organisation Mondiale de la Santé. Rapport sur la santé dans le monde 2002: réduire les risques et promouvoir une vie saine. Chapitre 4 - Quantification de certains risques majeurs pour la santé. OMS 2002, p 51-104.

[18] Summary of the second National Cholesterol Education Program (NCEP) Expert panel on Detection, Evaluation, and Treatment of High Blood Cholesterol in Adults (Adult Treatment Panel II). JAMA. 1993; 269: 3015-23. 